\title{
Quercetin extracted from Sophora japonica flower improves growth performance, nutrient digestibility, cecal microbiota, organ indexes, and breast quality in broiler chicks
}

\author{
De Xin Dang ${ }^{1, a}$, Sungbo Cho ${ }^{2, a}$, Huan Wang ${ }^{1,3}$, Woo Jeong Seok ${ }^{1}$, Jung Heun Ha ${ }^{4,5}$, and In Ho Kim ${ }^{1, *}$
}

\section{* Corresponding Author: In Ho Kim Tel: +82-41-550-3652, Fax: +82-41-559-7881, \\ E-mail: inhokim@dankook.ac.kr \\ 1 Department of Animal Resource and Science, Dankook University, Cheonan 31116, Korea 2 School of Mongolian Medicine, Inner Mongolia University for Nationalities, Tongliao, Inner Mongolia Autonomous Region 028000, China \\ ${ }^{3}$ School of Biology and Food Engineering, Chuzhou University, Chuzhou, 239000, China ${ }^{4}$ Department of Food Science and Nutrition, Dankook University, Cheonan 31116, Korea ${ }^{5}$ Research Center for Industrialization of Natural Neutralization, Dankook University, Cheonan 31116, Korea \\ a The first two authors contributed equally.}

ORCID

De Xin Dang

https://orcid.org/0000-0002-9672-8922 Sungbo Cho

https://orcid.org/0000-0002-2593-2758 Huan Wang

https://orcid.org/0000-0001-8955-7267 Woo Jeong Seok

https://orcid.org/0000-0002-1758-7579 Jung Heun $\mathrm{Ha}$

https://orcid.org/0000-0001-5282-531X In Ho Kim

https://orcid.org/0000-0001-6652-2504

Submitted Jul 23, 2021; Revised Sept 27, 2021; Accepted Nov 29, 2021
Objective: The objective of this study was to evaluate the effects of supplementing quercetin extracted from Sophora japonica flower (QS) to the diet of broiler chicks on their growth performance, apparent nutrient digestibility, cecal microbiota, serum lipid profiles, relative organ weight, and breast muscle quality.

Methods: A total of 1,088 1-day-old broiler chicks (mixed sex) were randomly assigned to four groups based on the initial body weight $(43.00 \pm 0.29 \mathrm{~g})$. The experimental period was 35 days (starter, days 0 to 7; grower, days 7 to 21; finisher, days 21 to 35). There were 17 replicate cages per treatment and 16 birds per cage. Dietary treatments consisted of birds receiving basal diet without quercetin as the control group and treatment groups consisted of birds fed basal diet supplemented with $0.2,0.4$, or $0.6 \mathrm{~g} / \mathrm{kg}$ QS.

Results: With the increase of the QS dosage, body weight gain during days 0 to 7 ( $\mathrm{p}=0.021$ ), 7 to $21(\mathrm{p}=0.010)$, and 1 to $35(\mathrm{p}=0.045)$, feed intake during days 0 to $7(\mathrm{p}=0.037)$ and 1 to $35(\mathrm{p}=0.025)$, apparent dry matter digestibility $(\mathrm{p}=0.008)$, apparent energy retention $(p=0.004)$, cecal lactic acid bacteria counts $(p=0.023)$, the relative weight of breast muscle $(\mathrm{p}=0.014), \mathrm{pH}$ value from breast muscle $(\mathrm{p}<0.001)$, and the water holding capacity of breast muscle $(\mathrm{p}=0.012)$ increased linearly, whereas the drip loss from breast muscle $(\mathrm{p}=0.001)$ decreased linearly.

Conclusion: The addition of QS in the diet of broiler chicks had positive effects on the breast muscle yield and breast muscle quality, and improved the dry matter digestibility and energy retention by increasing cecal beneficial bacteria counts, thus improving growth performance.

Keywords: Broiler Chick; Meat Quality; Nutrient Digestibility; Quercetin; Sophora japonica

\section{INTRODUCTION}

Flavonoids have a variety of biological activities and are widely used in the modern livestock industry [1-3]. It has been reported that flavonoid supplementation had beneficial effects on the improvement of growth performance, nutrient digestibility, intestinal microbiota community, immune status, and antioxidant status in poultry $[4,5]$.

Quercetin is a kind of flavonoid compound which is widely found in fruits or vegetables [6]. Quercetin has been widely reported for its excellent biological properties such as antibacterial, antioxidant, gut health improver, growth promoter, and immunomodulatory [7-10]. The sources of quercetin include chemical synthesis or plant extraction. It has been reported that dietary supplementation of chemically synthesized quercetin was not beneficial to the growth performance in broiler chicks $[8,11-16]$. Therefore, modern poultry husbandry focused on the quercetin derived from plants.

Zhang and Kim [17] reported that dietary supplementation of $0.25,0.50$, or $1.00 \mathrm{~g} / \mathrm{kg}$ 
plant-derived quercetin improved growth performance, cecal microbiota community, and relative organ weight in broiler chicks. Abid et al [18] reported that feeding broiler chicks with $0.1,0.2$, or $0.3 \mathrm{~g} / \mathrm{kg}$ quercetin extracted from locust trees containing diet improved the feed efficiency. Sohaib et al [19] reported that broiler chicks fed the diet supplemented with $0.1,0.2$, or $0.3 \mathrm{~g} / \mathrm{kg}$ plant-derived quercetin improved growth performance. However, no studies have evaluated the effects of dietary supplementation of quercetin extracted from the flower of Sophora japonica (QS) on growth performance in broiler chicks.

We hypothesized that supplementing QS to the diet of broiler chicks could improve the apparent nutrient digestibility by regulating the cecal microbiota community, thus improving growth performance. The objective of this study was to evaluate the effects of QS supplementation on growth performance, apparent nutrient digestibility, cecal microbiota, serum lipid profiles, relative organ weight, and breast muscle quality in broiler chicks.

\section{MATERIALS AND METHODS}

The experiment was conducted under the supervision of the Animal Care and Use Committee of Dankook University (Cheonan, South Korea), and the relevant experimental protocol has been approved (No. DK-1-2032).

\section{Animals, diets, and experimental design}

A total of 1,088 day-old (as hatched) Ross 308 broiler chicks (mixed sex) were randomly assigned to four groups based on the initial body weight $(43.00 \pm 0.29 \mathrm{~g})$. There were 17 replicate cages per treatment and 16 birds per cage. The experimental period was 35 days, including starter period (days 0 to 7 ), grower period (days 7 to 21), and finisher period (days 21 to 35). The dietary treatments used included: i) basal diet (no additive, control group), ii) basal diet including $0.2 \mathrm{~g} / \mathrm{kg}$ of QS, iii) basal diet including $0.4 \mathrm{~g} / \mathrm{kg}$ QS, and iv) basal diet including $0.6 \mathrm{~g} / \mathrm{kg}$ QS. The commercial quercetin additive (Synergen, 190, Sinheung, Bucheon, Gyeonggi, Korea) was $97 \%$ pure quercetin which was extracted from the flower of QS.

Table 1. Composition and nutrient levels of the experimental basal diet (\%, as-fed basis)

\begin{tabular}{|c|c|c|c|}
\hline \multirow{2}{*}{ Items } & \multicolumn{3}{|c|}{ Feeding phases } \\
\hline & Starter (days 0 to 7 ) & Grower (days 7 to 21) & Finisher (days 21 to 35) \\
\hline \multicolumn{4}{|l|}{ Ingredients (\%) } \\
\hline Soybean meal & 35.08 & 31.28 & 28.18 \\
\hline Corn gluten meal & 13.00 & 13.00 & 10.00 \\
\hline Wheat bran & 3.00 & 3.00 & 3.00 \\
\hline Limestone & 0.94 & 0.94 & 0.94 \\
\hline Salt & 0.36 & 0.36 & 0.36 \\
\hline Methionine (99\%) & 0.19 & 0.19 & 0.19 \\
\hline Lysine & 0.03 & 0.03 & 0.03 \\
\hline Mineral mix ${ }^{1)}$ & 0.10 & 0.10 & 0.10 \\
\hline Available P (\%) & 0.54 & 0.53 & 0.52 \\
\hline \multicolumn{4}{|l|}{ Analyzed composition } \\
\hline Crude protein (\%) & 23.00 & 21.50 & 20.00 \\
\hline $\mathrm{Ca}(\%)$ & 1.10 & 1.08 & 1.07 \\
\hline Total P (\%) & 0.83 & 0.82 & 0.79 \\
\hline Lys (\%) & 1.26 & 1.15 & 1.06 \\
\hline Met $(\%)$ & 0.54 & 0.52 & 0.50 \\
\hline Crude fat (\%) & 4.45 & 4.51 & 4.32 \\
\hline Crude fiber (\%) & 3.55 & 3.48 & 3.30 \\
\hline Crude ash (\%) & 6.76 & 6.57 & 6.30 \\
\hline
\end{tabular}

1) Provided per kg of complete diet: 37.5 mg Zn (zinc sulphate); 37.5 mg Mn (manganous oxide); 37.5 mg Fe (iron sulphate); 3.75 mg Cu (copper sulphate); $0.83 \mathrm{mg}$ I (potassium iodide); and $0.23 \mathrm{mg}$ Se (Sodium selenite).

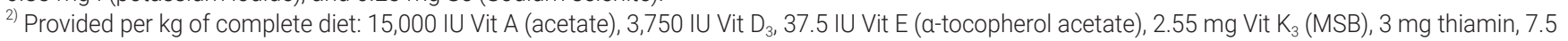
mg riboflavin, 4.5 mg Vit $B_{6}$ (pyridoxin-HCl), 24 ug Vit $B_{12}, 51$ mg niacin (niacinamide), 1.5 mg folic acid (crystalline), 0.2 mg biotin, and 13.5 mg Ca-Pantothenate. 
The birds were housed in 3-floor battery cages $(1.55 \times 0.75$ $\times 0.55 \mathrm{~m} /$ cage), in an environmentally controlled room (temperature was started at $32^{\circ} \mathrm{C}$ and reduced by $2^{\circ} \mathrm{C}$ every week up to $24^{\circ} \mathrm{C}$, and $65 \%$ relative humidity). The lighting program was $24 \mathrm{~h}$ a day for the first week (days 0 to 7 ) and then reduced to $16 \mathrm{~h}$ of light and $8 \mathrm{~h}$ of dark during 7 to 35 days. Each cage was equipped with 2 feeders (one feeder on each side) and 2 nipple drinkers to provide feed and water ad libitum to birds. Diets were formulated to meet the nutrient requirements recommended by the NRC (Table 1) [20] and provided in mash form.

\section{Sampling and measurements}

Body weight and feed intake (FI) in each replicate cage was recorded on the 0 th, 7 th, 21 st, and 35 th day to measure the body weight gain (BWG), FI, and feed conversion ratio (FCR). For deaths during the middle of a weighing period, the weight of dead animal was recorded, and the gain of the dead bird was counted towards pen gain in figuring feed conversion. The numbers of dead birds were examined as well.

On the 28th day, $2 \mathrm{~g} / \mathrm{kg}$ chromium oxide was added to the diet as an inert marker to measure the apparent total tract digestibility (ATTD) of dry matter (DM) and nitrogen (N), and the apparent retention of energy. The representative feed samples were taken after proper mixing and stored in the $-20^{\circ} \mathrm{C}$ freezer. During days 33 to 35 , excreta samples were collected from each replicate cage in duplicates and stored in a freezer at $-20^{\circ} \mathrm{C}$ until analysis. On day 35 , feed and excreta samples were thawed and dried at $60^{\circ} \mathrm{C}$ for $72 \mathrm{~h}$, then finely ground to pass through a 1-mm sieve and collected. Following the procedure established by the Association of Official Analytical Chemists (AOAC International) [21], diet samples were analyzed for DM (method 930.15), N (method 968.06), crude fiber (method 991.43), calcium (method 984.01), phosphorus (method 965.17), crude fat (method 954.02), and crude ash (method 942.05). Excreta powder samples were also analyzed for DM (method 930.15) and crude protein (method 968.06) following the procedures established by AOAC International [21]. The lysine and methionine content of the diets were measured using an AA analyzer (Beckman 6300; Beckman Coulter, Inc., Fillerton, CA, USA). The combustion heat was measured by a bomb calorimeter (Parr 6100; Parr Instrument Co., Moline, IL, USA) to determine the gross energy content of the feed and excreta powder samples. Chromium concentration was determined by atomic absorption spectrophotometry (UV1201, Shimadzu, Kyoto, Japan). The equation for calculating digestibility was as follows:

$$
\text { Digestibility (\%) }=\left(1-\frac{N f \times C d}{N d \times C f}\right) \times 100
$$

where $\mathrm{Nf}=$ nutrient concentration in excreta $(\% \mathrm{DM}), \mathrm{Nd}$ $=$ nutrient concentration in diet $(\% \mathrm{DM}), \mathrm{Cf}=$ chromium concentration in excreta $(\% \mathrm{DM})$, and $\mathrm{Cd}=$ chromium concentration in diet (\% DM).

At the end of the experimental period, 68 birds ( 4 birds per replicate cage) were randomly selected from each treatment and blood samples were collected from the wing vein using a sterile syringe and stored at $4^{\circ} \mathrm{C}$. Samples for serum analysis were then centrifuged at $3,000 \times g$ for $15 \mathrm{~min}$ at $4^{\circ} \mathrm{C}$. Total cholesterol, triglyceride, low-density lipoprotein cholesterol (LDL-C) and high-density lipoprotein cholesterol (HDL-C) concentrations in serum were determined enzymatically using reagent kits (Wako Pure Chemical Industries Ltd., Tokyo, Japan).

After blood collection, they were slaughtered by cervical dislocation. The breast muscle, liver, abdominal fat, bursa of fabricius, and gizzard were removed and weighed to calculate the relative organ weight. The breast muscle was removed and stored at $2^{\circ} \mathrm{C}$ for the measurement of meat quality. The organ index was calculated using the following equation:

$$
\text { Organ } \text { index }=\frac{\text { Organ weight }}{\text { Live body weight }} \times 100 \%
$$

After slaughtering the birds, fresh digesta content samples were collected from the caecum into micro-tubes. One gram of digesta sample was blended with $9 \mathrm{~mL}$ sterile peptone water and mixed for $1 \mathrm{~min}$ on a vortex stirrer. Counts of viable bacteria in the caecum samples were determined by plating serial 10 -fold dilutions $\left(10^{-3}\right.$ to $\left.10^{-6}\right)$ onto Lactobacilli MRS agar (Difco Laboratories, Detroit, MI, USA), MacConkey agar (Difco Laboratories, USA), and Salmonella-Shigella (SS) agar (Difco Laboratories, USA) plates to isolate lactic acid bacteria, coliform bacteria, and Salmonella, respectively. The lactobacilli agar plates were then incubated for $24 \mathrm{~h}$ at $37^{\circ} \mathrm{C}$ under anaerobic conditions. The MacConkey and SS agar plates were incubated for $24 \mathrm{~h}$ at $37^{\circ} \mathrm{C}$ under aerobic conditions. After the incubation periods, colonies of the respective bacteria were counted and expressed as the logarithm of colony-forming units per gram $\left(\log _{10} \mathrm{CFU} / \mathrm{g}\right)$.

The $\mathrm{pH}$ values of each breast meat sample were measured in duplicate using a pH meter (Fisher Scientific, Pittsburgh, PA, USA). Thereafter, a $0.20 \mathrm{~g}$ meat sample was pressed at $20.7 \mathrm{MPa}$ for 3 minutes on a $125-\mathrm{mm}$-diameter piece of filter paper. The areas of the pressed sample and the expressed moisture were delineated and then determined using a digitizing area-line sensor (MT-10S; M.T. Precision Co. Ltd., Tokyo, Japan) to calculate the water holding capacity (WHC). About $5 \mathrm{~g}$ of meat sample was suspended in a zipper bag in a $4^{\circ} \mathrm{C}$ environment and weighed on the 1 st day to calculate the drip loss. 


\section{Statistical analysis}

All data were subjected to statistical analysis in a randomized complete block design using the General Linear Model procedure (SAS Inst. Inc., Cary, NC, USA). The replicate cage was used as the experimental unit. Orthogonal contrasts were used to examine the linear and quadratic effects in response to increasing the dietary supplementation of QS. Variability in the data was expressed as the standard error of means, $\mathrm{p}<0.05$ is considered statistically significant.

\section{RESULTS}

The BWG during days 0 to $7(\mathrm{p}=0.021), 7$ to $21(\mathrm{p}=0.010)$, and 1 to $35(\mathrm{p}=0.045)$, and FI during days 0 to $7(\mathrm{p}=0.037)$ and 1 to $35(\mathrm{p}=0.025)$ increased linearly with the increase in the QS levels in the diet. However, the FCR did not differ among all dietary groups (Table 2).

Supplementing graded levels of QS to the diet of broiler chicks linearly increased apparent DM digestibility $(\mathrm{p}=0.008)$ and apparent energy retention $(\mathrm{p}=0.004)$, whereas it did not affect the apparent nitrogen digestibility (Table 3 ).
Dietary supplementation of QS had no significant effects on the serum total cholesterol, triglyceride, HDL-C, and LDL-C concentrations (Table 4).

The counts of lactic acid bacteria $(\mathrm{p}=0.023)$ increased linearly as the dose of QS increased in the diet. However, the coliform bacteria and Salmonella counts in cecal contents were not differ among all dietary groups (Table 5).

Broiler chicks fed the diet supplemented with QS linearly increased the relative weight of breast muscle $(p=0.014)$, while liver, abdominal fat, bursa of fabricius, and gizzard were not affected, with the increase of the QS dosage. In addition, supplementing graded levels of QS to the diet of broiler chicks linearly increased $\mathrm{pH}$ value $(\mathrm{p}<0.001)$ and WHC $(\mathrm{p}=0.012)$ from breast muscle, while linearly decreased drip loss ( $\mathrm{p}=$ 0.001 ) from breast muscle as the dose of QS increased (Table $6)$.

\section{DISCUSSION}

Reports on the effects of dietary supplementation of quercetin on the growth performance of broiler chicks were

Table 2. Effect of dietary supplementation of quercetin extracted from the flower of Sophora japonica (QS) on growth performance of broiler chicks

\begin{tabular}{|c|c|c|c|c|c|c|c|}
\hline \multirow{2}{*}{ Items } & \multicolumn{4}{|c|}{ QS (g/kg) } & \multirow{2}{*}{ SEM } & \multicolumn{2}{|c|}{$\mathrm{p}$-value } \\
\hline & 0.0 & 0.2 & 0.4 & 0.6 & & Linear & Quadratic \\
\hline Initial body weight (g) & 42.75 & 42.88 & 43.03 & 43.34 & 0.288 & 0.151 & 0.751 \\
\hline \multicolumn{8}{|l|}{ Body weight gain (g) } \\
\hline Days 0 to 7 & 125.93 & 129.16 & 132.25 & 132.21 & 1.959 & 0.021 & 0.414 \\
\hline Days 7 to 21 & 650.48 & 667.19 & 662.75 & 673.27 & 5.010 & 0.010 & 0.544 \\
\hline Days 21 to 35 & 939.63 & 988.80 & 960.52 & 987.32 & 20.269 & 0.220 & 0.587 \\
\hline Days 0 to 35 & $1,716.03$ & $1,785.15$ & $1,755.52$ & $1,792.80$ & 20.948 & 0.045 & 0.456 \\
\hline \multicolumn{8}{|l|}{ Feed intake (g) } \\
\hline Days 0 to 7 & 148.33 & 147.04 & 156.94 & 153.70 & 2.609 & 0.037 & 0.713 \\
\hline Days 7 to 21 & $1,004.74$ & $1,010.83$ & $1,015.35$ & $1,033.50$ & 12.582 & 0.122 & 0.637 \\
\hline Days 21 to 35 & $1,710.14$ & $1,768.96$ & $1,744.97$ & $1,761.56$ & 18.865 & 0.138 & 0.276 \\
\hline Days 0 to 35 & 2,863.21 & $2,926.83$ & $2,917.27$ & $2,948.76$ & 22.736 & 0.025 & 0.488 \\
\hline \multicolumn{8}{|l|}{ FCR } \\
\hline Days 0 to 7 & 1.18 & 1.14 & 1.19 & 1.16 & 0.023 & 0.997 & 0.735 \\
\hline Days 7 to 21 & 1.55 & 1.52 & 1.53 & 1.54 & 0.021 & 0.896 & 0.453 \\
\hline Days 21 to 35 & 1.82 & 1.79 & 1.82 & 1.79 & 0.030 & 0.514 & 0.939 \\
\hline Days 0 to 35 & 1.67 & 1.64 & 1.66 & 1.65 & 0.013 & 0.389 & 0.664 \\
\hline Mortality (\%) & 0.03 & 0.03 & 0.03 & 0.03 & 0.016 & - & - \\
\hline
\end{tabular}

SEM, standard error of the mean; FCR, feed conversion ratio.

Table 3. Effect of dietary supplementation of quercetin extracted from the flower of Sophora japonica (QS) on apparent nutrient digestibility of broiler chicks (\%)

\begin{tabular}{|c|c|c|c|c|c|c|c|}
\hline \multirow{2}{*}{ Items } & \multicolumn{4}{|c|}{ QS (g/kg) } & \multirow{2}{*}{ SEM } & \multicolumn{2}{|c|}{ p-value } \\
\hline & 0.0 & 0.2 & 0.4 & 0.6 & & Linear & Quadratic \\
\hline DM & 70.06 & 70.47 & 71.38 & 72.93 & 0.759 & 0.008 & 0.451 \\
\hline Nitrogen & 63.70 & 65.94 & 65.29 & 66.47 & 1.030 & 0.104 & 0.611 \\
\hline Energy & 71.01 & 71.47 & 71.96 & 73.73 & 0.634 & 0.004 & 0.307 \\
\hline
\end{tabular}

SEM, standard error of the mean; DM, dry matter. 
Table 4. Effect of dietary supplementation of quercetin extracted from the flower of Sophora japonica (QS) on serum cholesterol profiles of broiler chicks

\begin{tabular}{|c|c|c|c|c|c|c|c|}
\hline \multirow{2}{*}{ Items } & \multicolumn{4}{|c|}{ QS (g/kg) } & \multirow{2}{*}{ SEM } & \multicolumn{2}{|c|}{ p-value } \\
\hline & 0.0 & 0.2 & 0.4 & 0.6 & & Linear & Quadratic \\
\hline Total cholesterol (mg/dL) & 117.58 & 116.25 & 116.00 & 120.75 & 1.908 & 0.284 & 0.118 \\
\hline Triglyceride (mg/dL) & 28.75 & 28.25 & 28.00 & 26.75 & 1.650 & 0.402 & 0.821 \\
\hline $\mathrm{HDL}-\mathrm{C}(\mathrm{mg} / \mathrm{dL})$ & 80.92 & 80.50 & 80.50 & 82.75 & 1.559 & 0.434 & 0.397 \\
\hline LDL-C (mg/dL) & 30.92 & 30.10 & 29.90 & 32.65 & 1.688 & 0.511 & 0.297 \\
\hline
\end{tabular}

SEM, standard error of the mean; HDL-C, high-density lipoprotein cholesterol; LDL-C, low-density lipoprotein cholesterol.

Table 5. Effect of dietary supplementation of quercetin extracted from the flower of Sophora japonica (QS) on cecal microbiota of broiler chicks

\begin{tabular}{|c|c|c|c|c|c|c|c|}
\hline \multirow{2}{*}{ Items } & \multicolumn{4}{|c|}{ QS (g/kg) } & \multirow{2}{*}{ SEM } & \multicolumn{2}{|c|}{ p-value } \\
\hline & 0.0 & 0.2 & 0.4 & 0.6 & & Linear & Quadratic \\
\hline Lactic acid bacteria $\left(\log _{10} \mathrm{cfu} / \mathrm{g}\right)$ & 7.40 & 7.58 & 7.52 & 7.74 & 0.091 & 0.023 & 0.841 \\
\hline Coliform bacteria $\left(\log _{10} \mathrm{cfu} / \mathrm{g}\right)$ & 6.28 & 6.18 & 6.07 & 6.03 & 0.133 & 0.158 & 0.800 \\
\hline Salmonella $\left(\log _{10} \mathrm{cfu} / \mathrm{g}\right)$ & 5.37 & 5.04 & 4.96 & 5.01 & 0.177 & 0.148 & 0.296 \\
\hline
\end{tabular}

SEM, standard error of the mean.

inconsistent. Goliomytis et al [12] reported that feeding broiler chicks with 0.5 or $1.0 \mathrm{~g} / \mathrm{kg}$ quercetin dihydrate compound containing diet had no effects on the BWG and FI, but increased FCR. In addition, many studies have reported that the growth performance was not affected in broiler chicks fed with a chemically synthesized quercetin containing diet $[13,14,16,22]$. Conversely, Abid et al [18] reported that supplementing $0.1,0.2$, or $0.3 \mathrm{~g} / \mathrm{kg}$ quercetin extracted from the locust tree to the diet of broiler chicks had positive effects on the growth performance. Sohaib et al [19] fed broiler chicks with $0.1,0.2$, or $0.3 \mathrm{~g} / \mathrm{kg}$ plant-derived quercetin containing diet and found an increase of BWG and a decrease of FCR compared with those fed with the control diet. Zhang and Kim [17] observed the increase of BWG in broiler chicks fed the diet supplemented with $0.25,0.50$, or $1.0 \mathrm{~g} / \mathrm{kg}$ plant-derived quercetin. In the present study, the improvement of growth performance was also observed in broiler chicks fed with QS containing diet. The different effects of quercetin supplementation on the growth performance of broiler chicks may be due to the different sources of quercetin. According to the report of Rasouli and Jahanian [23], the improvement of growth performance in broiler chicks could be achieved by regulating the intestinal microbiota community.

It is well known that the distribution and quantity of intestinal microbiota communities directly affect the health and growth of broiler chicks [24]. A high level of intestinal beneficial bacteria is beneficial to improve nutrient digestibility [24]. Abolfathi et al [25] reported the strategy for improving the nutrient digestibility by increasing intestinal lactic acid bacteria counts in feeding broiler chicks with flavonoidenriched herbal extract, thus improving growth performance. In this study, we also observed the improvement of apparent DM digestibility, energy retention, and the counts of cecal lactic acid bacteria by QS supplementation. It has been reported that the quercetin and lactic acid bacteria co-cultured

Table 6. Effect of dietary supplementation of quercetin extracted from the flower of Sophora japonica (QS) on carcass traits of broiler chicks

\begin{tabular}{|c|c|c|c|c|c|c|c|}
\hline \multirow{2}{*}{ Items } & \multicolumn{4}{|c|}{ QS (g/kg) } & \multirow{2}{*}{ SEM } & \multicolumn{2}{|c|}{$\mathrm{p}$-value } \\
\hline & 0.0 & 0.2 & 0.4 & 0.6 & & Linear & Quadratic \\
\hline \multicolumn{8}{|c|}{ Relative organ weight (\%) } \\
\hline Breast muscle & 18.09 & 19.31 & 19.15 & 19.40 & 0.328 & 0.014 & 0.145 \\
\hline Liver & 2.60 & 2.52 & 2.57 & 2.54 & 0.025 & 0.315 & 0.291 \\
\hline Abdominal fat & 1.14 & 0.85 & 1.04 & 1.00 & 0.099 & 0.604 & 0.190 \\
\hline Bursa of Fabricius & 0.21 & 0.18 & 0.18 & 0.18 & 0.015 & 0.170 & 0.414 \\
\hline Gizzard & 1.55 & 1.39 & 1.54 & 1.54 & 0.066 & 0.694 & 0.244 \\
\hline \multicolumn{8}{|l|}{ Breast muscle quality } \\
\hline $\mathrm{pH}$ value & 5.43 & 5.70 & 5.65 & 5.86 & 0.055 & $<0.001$ & 0.609 \\
\hline WHC (\%) & 47.31 & 52.21 & 49.16 & 53.11 & 1.229 & 0.012 & 0.703 \\
\hline Drip loss (\%) & 2.25 & 1.99 & 1.92 & 1.75 & 0.095 & 0.001 & 0.636 \\
\hline
\end{tabular}

SEM, standard error of the mean; WHC, water-holding capacity. 
in vitro showed that quercetin increased the hydrophobicity of cell surface and improved the auto-aggregation and coaggregation capacity of lactic acid bacteria [26]. The hydrophobicity and aggregation of cell surface are related to the ability of probiotics to adhere to the intestinal mucosa $[26,27]$, which means quercetin has modulatory effects on lactic acid bacteria. Studies on the metabolism of quercetin and flavonoids in vivo of broiler chicks, humans, and rats have shown that dietary quercetin is absorbed in a small percentage (below 10\%) in the small intestine due to the high hydrophobicity of quercetin and the high hydrophobicity of the intestinal mucus layer. The rest of these compounds reach the colon and exert biochemical activity in an unabsorbed form [6,28-30]. Therefore, the lactic acid bacteria modulation effects of quercetin as mentioned above possibly occurred in the colon. In addition, quercetin has been reported to exert potential prebiotic effects in vivo [31], thus promoting the growth of intestinal beneficial bacteria [24]. Therefore, the improvement of the counts of lactic acid bacteria by quercetin supplementation is probably related to its lactic acid bacteria modulatory ability and the prebiotic effects. Similar to our results, Zhang and Kim [17] reported that broiler chicks fed the diet supplemented with $0.25,0.50$, or $1.0 \mathrm{~g} / \mathrm{kg}$ plant-derived quercetin increased cecal lactic acid bacteria counts, but the coliform bacteria and Salmonella counts in cecal contents were not affected. Wang et al [24] noted that supplementing $0.2 \mathrm{~g} / \mathrm{kg}$ chemically synthesized quercetin to the diet of broiler chicks increased cecal lactic acid bacteria counts. In addition, Zhao et al [32] found that dietary supplementation of quercetin-containing antioxidant substance complexes could reverse the decrease of lactic acid bacteria in the intestine of broiler chicks caused by feeding with a high-fat diet. Therefore, we considered that the improvement of apparent DM digestibility and energy retention were related to the increase of the counts of cecal lactic acid bacteria in broiler chicks fed with QS containing diet, thus benefiting to the improvement of growth performance.

Moreover, Yang et al [33] mentioned that feeding birds with quercetin containing diet increased serum growth hormone (insulin-like growth factor-1) concentrations. Dong et al [34] mentioned that the antioxidant status of broiler chicks improved by quercetin supplementation. Further experiments are needed to explore the effects of dietary supplementation of QS on serum growth hormone concentrations and the antioxidant parameters, so as to reveal the endocrine mechanism of QS supplementation promoting the growth performance of broiler chicks. In brief, the growth promoting effect of QS supplementation in broiler chicks was confirmed in this study.

Too much abdominal fat negatively affected the commercial value of the carcass of broiler chicks [35]. It has been reported that quercetin has properties in fat metabolism regulation [36,37]. The lipid deposition regulation properties of quercetin are achieved by modulating the lipid synthesized in hepatocytes [38]. Quercetin could reduce lipid deposition in broiler chicks by promoting PPARa-regulated lipid decomposition [38], reducing the expression levels of sterol regulatory element-binding protein 1 , peroxisome proliferatoractivated receptor gamma, and 3-hydroxy-3-methylglutarylCoA reductase in the liver [39], and activating P13K/PKB, AMRK, and/or cAMP signal pathway [39-41]. It has been reported that quercetin supplementation reduced the increase of adipose tissue weight induced by feeding with a high-fat diet in rats $[32,42,43]$. The content of total cholesterol, LDL$\mathrm{C}, \mathrm{HDL}-\mathrm{C}$, and triglyceride in serum are key indicators of lipid metabolism $[38,44,45]$. In this study, the concentrations of serum total cholesterol, LDL-C, HDL-C, and triglyceride were not affected by QS supplementation. Similarly, Yugarani et al [46] found that quercetin supplementation had no significant effects on the serum total cholesterol and triglyceride concentrations in rats fed with a high-fat diet. Egert et al [47] reported that quercetin supplementation had no significant effects on the serum total cholesterol concentrations in humans. Simitzis et al [48] demonstrated that the serum total cholesterol concentrations in laying hens fed with $0.2,0.4$, or $0.8 \mathrm{~g} / \mathrm{kg}$ quercetin containing diet was not affected. The liver is the site for lipid metabolism, the variation of its weight reflects the level of metabolic activity intensity [49]. In this study, supplementing QS to the diet of broiler chicks had no significant effects on the relative weight of the liver, which probably means that the lipid metabolic activity intensity was not affected by QS supplementation, which was manifested in the stable serum total cholesterol, LDL-C, HDL-C, and triglyceride concentrations. This is probably the reason for insignificant effects on the relative weight of abdominal fat. Similarly, Goliomytis et al [12] reported that supplementing 0.5 or $1.0 \mathrm{~g} / \mathrm{kg}$ quercetin had no significant effects on the relative weight of liver and abdominal fat in broiler chicks. Therefore, we considered that the QS supplementation may not regulate the relative weight of abdominal fat.

The high relative weight of breast muscle is beneficial to the market value of broiler chicks [50]. In the present study, dietary supplementation of QS increased the relative weight of breast muscle. Similarly, Zhang and Kim [17] also observed the increasing trend of the relative weight of breast muscle in broiler chicks fed with quercetin containing diet. It has been reported that flavonoid supplementation in the diet of broiler chicks could increase breast muscle weight [51]. Chan et al [52] reported that quercetin prevented the muscle wasting induced by trichostatin A. Kamboh and Zhu [53] proved that the flavonoid increased the protein synthesis in muscle. Liu et al [54] mentioned that quercetin promoted the protein synthesis of laying hens in vivo. In general, feeding broiler 
chicks with QS containing diet was beneficial to increase the relative weight of breast muscle, thus may enhance their market value.

Gizzard is one of the main digestive organs as it is involved in grinding and proteolysis [55]. It has been reported that diet supplemented with structural components which stimulate gizzard development improved nutrient availability [55]. In this study, the relative weight of the gizzard was not affected by QS supplementation, but the apparent DM digestibility and energy retention was improved. Parmar et al [15] reported that dietary supplementation of quercetin had no significant effects on the relative weight of gizzard. Therefore, supplementing QS to the diet of broiler chicks may not improve DM digestibility and energy retention by increasing the relative weight of gizzard, which was confirmed by the study of Zhang and Kim [17].

The bursa of fabricius is the important immune organ in broiler chicks [13]. Reduced weight of the immune organs represents immunosuppression, while an increase in the weight of immune organs is a manifestation of the enhancement of immunity [56]. Plenty of studies proved that quercetin supplementation had no significant effects on the bursa of fabricius indexes $[16,17,34]$. We also observed the same result that relative weight of bursa of fabricius was not significantly reduced by supplementing QS to the diet of broiler chicks.

The breast muscle of broiler chicks is among the most popular meats in the world [57]. WHC and drip loss are the important indexes to evaluate meat quality $[58,59]$. Moisture loss leads to the loss of soluble flavor substances in meat [60]. It has been reported that the variation of WHC and drip loss were dependent on the $\mathrm{pH}$ [61]. Jiang et al [62] reported that flavonoid supplementation resulted in the increase of $\mathrm{pH}$ in the breast muscle, which attributed to the improvement of antioxidant status of breast muscle. Several studies have proved that quercetin is deposited in the breast muscle of broiler chicks when they are fed a quercetin containing diet $[6,19,63]$. This makes it possible for quercetin to have an antioxidant effect on breast muscle. Goliomytis et al [12] reported that due to the accumulation of quercetin metabolites in the body tissues, it had the effect of reducing lipid oxidation rates. Therefore, it is reasonable to consider that the high $\mathrm{pH}$ value of breast muscle caused by QS supplementation was related to the improvement of antioxidant status $[12,64]$. However, further experiments are needed to evaluate the effects of QS supplementation on the antioxidant status of breast muscle. On the other hand, WHC and drip loss are dependent on the content of protein in muscle [65]. The protein synthesis properties of flavonoids in the muscle have been proved by Kamboh and Zhu [53]. Liu et al [54] reported that quercetin could promote the protein synthesis of laying hens in vivo. In this study, supplement- ing QS to the diet of broiler chicks increased the relative weight of breast muscle, which means that the QS supplementation probably increased protein synthesis in the muscle, thus benefiting the improvement of WHC and drip loss. In brief, dietary supplementation of QS is beneficial to increase WHC and decrease drip loss, which probably improves the acceptability of the meat to consumers [66].

\section{CONCLUSION}

Dietary supplementation of QS had positive effects on growth performance, apparent DM digestibility, apparent energy retention, cecal beneficial microbiota counts, breast muscle yield, and breast meat quality. This study confirmed the positive effects of QS on the growth performance of broiler chicks, and indicated that QS has potential for improving the performance and enhancing some aspects of the meat quality in poultry.

\section{CONFLICT OF INTEREST}

We certify that there is no conflict of interest with any financial organization regarding the material discussed in the manuscript.

\section{FUNDING}

The authors received no financial support for this article.

\section{REFERENCES}

1. González-Gallego J, García-Mediavilla MV, Sánchez-Campos S, Tuñón MJ. Fruit polyphenols, immunity and inflammation. Br J Nutr 2010;104:S15-27. https://doi.org/10.1017/ S0007114510003910

2. Georgiev V, Ananga A, Tsolova V. Recent advances and uses of grape flavonoids as nutraceuticals. Nutrients 2014;6:391415. https://doi.org/10.3390/nu6010391

3. Oboh G, Ademosun AO, Ogunsuyi OB. Quercetin and its role in chronic diseases. In: Gupta S, Prasad S, Aggarwal B, editors. Drug discovery from mother nature. Springer-Cham; 2016. p. 377-87. https://doi.org/10.1007/978-3-319-413426_17

4. Kamboh AA, Khan MA, Kaka U, et al. Effect of dietary supplementation of phytochemicals on immunity and haematology of growing broiler chickens. Ital J Anim Sci 2018; 17:1038-43. https://doi.org/10.1080/1828051X.2018.1438854

5. Sun HY, Kim YM, Kim IH. Evaluation of Achyranthes japonica Nakai extract on growth performance, nutrient utilization, cecal microbiota, excreta noxious gas emission, and meat quality in broilers fed corn-wheat-soybean meal diet. Poult Sci 2020;99:5728-35. https://doi.org/10.1016/j.psj.2020.07. 
023

6. Rupasinghe HP, Ronalds CM, Rathgeber B, Robinson RA. Absorption and tissue distribution of dietary quercetin and quercetin glycosides of apple skin in broiler chickens. J Sci Food Agric 2010;90:1172-8. https://doi.org/10.1002/jsfa. 3944

7. Boots AW, Drent M, de Boer VCJ, Bast A, Haenen GRMM. Quercetin reduces markers of oxidative stress and inflammation in sarcoidosis. Clin Nutr 2011;30:506-12. https:// doi.org/10.1016/j.clnu.2011.01.010

8. Liu HN, Liu Y, Hu LL, et al. Effects of dietary supplementation of quercetin on performance, egg quality, cecal microflora populations, and antioxidant status in laying hens. Poult Sci 2014;93:347-53. https://doi.org/10.3382/ps.2013-03225

9. Ognik K, Cholewinska E, Czech A. The effect of adding hesperidin, diosmin, quercetin and resveratrol extracts to feed for turkey hens on selected immunological and biochemical blood indices. Ann Anim Sci 2016;16:1101-14. https:// doi.org/10.1515/aoas-2016-0035

10. Hong Z, Piao M. Effect of quercetin monoglycosides on oxidative stress and gut microbiota diversity in mice with dextran sodium sulphate-induced colitis. BioMed Res Int 2018;2018:8343052. https://doi.org/10.1155/2018/8343052

11.Hager-Theodorides AL, Goliomytis M, Delis S, Deligeorgis S. Effects of dietary supplementation with quercetin on broiler immunological characteristics. Anim Feed Sci Technol 2014; 198:224-30. https://doi.org/10.1016/j.anifeedsci.2014.09.021

12. Goliomytis M, Tsoureki D, Simitzis PE, Charismiadou MA, Hager-Theodorides AL, Deligeorgis SG. The effects of quercetin dietary supplementation on broiler growth performance, meat quality, and oxidative stability. Poult Sci 2014;93:195762. https://doi.org/10.3382/ps.2013-03585

13. Van Krimpen MM, Torki M, Schokker D, et al. Effect of nutritional interventions with quercetin, oat hulls, $\beta$-glucans, lysozyme, and fish oil on immune competence related parameters of adult broiler. Wageningen Livest Res Rep 2016;977: 50. https://doi.org/10.18174/390435

14.Torki M, Schokker D, Duijster-Lensing M, van Krimpen MM. Effect of nutritional interventions with quercetin, oat hulls, $\beta$-glucans, lysozyme and fish oil on performance and health status related parameters of broilers chickens. Br Poult Sci 2018;59:579-90. https://doi.org/10.1080/00071668.2018. 1496402

15. Parmar AB, Patel VR, Usadadia SV, Chaudhary LM, Prajapati $\mathrm{DR}$, Londhe AS. Influence of dietary inclusion of oil and Quercetin supplementation on carcass characters and meat quality attributes of broiler chickens. Int J Livest Res 2019;9: 93-103. https://doi.org/10.5455/ijlr.20190629072333

16. Yang JX, Maria TC, Zhou B, et al. Quercetin improves immune function in Arbor Acre broilers through activation of NF- $\mathrm{\kappa B}$ signaling pathway. Poult Sci 2020;99:906-13. https:/doi.org/ 10.1016/j.psj.2019.12.021
17.Zhang S, Kim IH. Effect of quercetin (flavonoid) supplementation on growth performance, meat stability, and immunological response in broiler chickens. Livest Sci 2020;242:104286. https://doi.org/10.1016/j.livsci.2020.104286

18. Abid AR, Areaaer AH, Hussein MA, Gatea SM, Al-Nuaimi AJ. impact of different levels of quercetin on productive performance of broiler chicken (Ross-308). AIP Conf Proc 2020;2290:020046. https://doi.org/10.1063/5.0028377

19.Sohaib M, Butt MS, Shabbir MA, Shahid M. Lipid stability, antioxidant potential and fatty acid composition of broilers breast meat as influenced by quercetin in combination with a-tocopherol enriched diets. Lipids Health Dis 2015;14:61. https://doi.org/10.1186/s12944-015-0058-6

20. National Research Council. Nutrient requirements of poultry. 9th ed. Washington, DC, USA: National Academy Press; 1994.

21. Official methods of analysis of AOAC International. 17th ed. Washington, DC, USA: AOAC International; 2000.

22.Parmar AB, Patel VR, Dangar NS. Efficiency of dietary supplementation of flavonoid (Quercetin), vegetable oil and its combination on growth traits and feed conversion in broilers. J Anim Res 2020;10:557-62. https://doi.org/10.30954/ 2277-940X.04.2020.12

23. Rasouli E, Jahanian R. Comparative effects of genistein and antibiotics on performance, meat oxidative stability, jejunal morphology, and ileal microbial community in broiler chicks. Anim Feed Sci Technol 2019;256:114153. https://doi.org/ 10.1016/j.anifeedsci.2019.03.005

24. Wang S, Yao J, Zhou B, et al. Bacteriostatic effect of quercetin as an antibiotic alternative in vivo and its antibacterial mechanism in vitro. J Food Prot 2018;81:68-78. https://doi.org/ 10.4315/0362-028X.JFP-17-214

25. Abolfathi ME, Tabeidian SA, Shahraki ADF, Tabatabaei SN, Habibian M. Comparative effects of $\mathrm{n}$-hexane and methanol extracts of elecampane (Inula helenium L.) rhizome on growth performance, carcass traits, feed digestibility, intestinal antioxidant status and ileal microbiota in broiler chickens. Archiv Anim Nutr 2019;73:88-110. https://doi.org/10.1080/174503 9X.2019.1581027

26. Dos Santos AS, de Albuquerque TMR, de Brito Alves JL, de Souza EL. Effects of quercetin and resveratrol on in vitro properties related to the functionality of potentially probiotic lactobacillus strains. Front Microbiol 2019;10:2229. https:// doi.org/10.3389/fmicb.2019.02229

27.Deepika G, Rastall RA, Charalampopoulos D. Effect of food models and low-temperature storage on the adhesion of Lactobacillus rhamnosus GG to Caco-2 cells. J Agric Food Chem 2011;59:8661-6. https://doi.org/10.1021/jf2018287

28. Cardona F, Andrés-Lacueva C, Tulipani S, Tinahones FJ, Queipo-Ortuño MI. Benefits of polyphenols on gut microbiota and implications in human health. J Nutr Biochem 2013;24:1415-22. https://doi.org/10.1016/j.jnutbio.2013.05. 
001

29. Etxeberria U, Arias N, Boqué N, et al. Reshaping faecal gut microbiota composition by the intake of trans-resveratrol and quercetin in high-fat sucrose diet-fed rats. J Nutr Biochem 2015;26:651-60. https://doi.org/10.1016/j.jnutbio.2015.01.002

30. Gonzales GB, Camp JV, Smagghe G, Raes K, Mackie A. Flavonoid-gastrointestinal mucus interaction and its potential role in regulating flavonoid bioavailability and mucosal biophysical properties. Food Res Int 2016;88:342-7. https://doi. org/10.1016/j.foodres.2015.12.023

31.Porras D, Nistal E, Martínez-Flórez S, et al. Protective effect of quercetin on high-fat diet-induced non-alcoholic fatty liver disease in mice is mediated by modulating intestinal microbiota imbalance and related gut-liver axis activation. Free Radic Biol Med 2017;102:188-202. https://doi.org/10. 1016/j.freeradbiomed.2016.11.037

32.Zhao L, Zhang Q, Ma W, Tian F, Shen H, Zhou M. A combination of quercetin and resveratrol reduces obesity in highfat diet-fed rats by modulation of gut microbiota. Food Funct 2017;8:4644-56. https://doi.org/10.1039/C7FO01383C

33. Yang JX, Chaudhry MT, Yao JY, et al. Effects of phyto-oestrogen quercetin on productive performance, hormones, reproductive organs and apoptotic genes in laying hens. J Anim Physiol Anim Nutr 2018;102:505-13. https://doi.org/ 10.1111/jpn. 12778

34.Dong Y, Lei J, Zhang B. Effects of dietary quercetin on the antioxidative status and cecal microbiota in broiler chickens fed with oxidized oil. Poult Sci 2020;99:4892-903. https:// doi.org/10.1016/j.psj.2020.06.028

35. Musa HH, Chen GH, Cheng JH, Li BC, Mekki DM. Study on carcass characteristics of chicken breeds raised under the intensive condition. Int J Poult Sci 2006;5:530-3. https://doi. org/10.3923/ijps.2006.530.533

36.Peng J, Li Q, Li K, et al. Quercetin improves glucose and lipid metabolism of diabetic rats: involvement of akt signaling and SIRT1. J Diabetes Res 2017;2017:Article ID 3417306. https://doi.org/10.1155/2017/3417306

37. Rocca C, Albano L, Granieri MC, et al. Novel anti-obesity quercetin-derived Q2 prevents metabolic disorders in rats fed with high-fat diet. Vascul Pharmacol 2018;103-5:58. https://doi.org/10.1016/j.vph.2017.12.030

38. Wang M, Xiao FL, Mao YJ, Ying LL, Zhou B, Li Y. Quercetin decreases the triglyceride content through the PPAR signalling pathway in primary hepatocytes of broiler chickens. Biotechnol Biotechnol Equip 2019;33:1000-10. https://doi.org/10.1080/ 13102818.2019.1635528

39. Wang M, Wang B, Wang S, et al. Effect of quercetin on lipids metabolism through modulating the gut microbial and AMPK/PPAR signaling pathway in broilers. Front Cell Dev Biol 2021;9:616219. https://doi.org/10.3389/fcell.2021.616219

40. Ouyang WW, Li Y, Zhao W, Wang M, Jin F. Effect of quercetin on cAMP signaling pathway in chicken adipocytes. Scientia
Agricultura Sinica 2013;46:2769-76.

41. Ying L, Chaudhry MT, Xiao F, et al. The effects and mechanism of quercetin dietary supplementation in streptozotocininduced hyperglycemic arbor acre broilers. Oxid Med Cell Longev 2020;2020:9585047. https://doi.org/10.1155/2020/ 9585047

42.Panchal SK, Poudyal H, Brown L. Quercetin ameliorates cardiovascular, hepatic, and metabolic changes in dietinduced metabolic syndrome in rats. J Nutr 2012;142:102632. https://doi.org/10.3945/jn.111.157263

43. Kim CS, Kwon Y, Choe SY, et al. Quercetin reduces obesityinduced hepatosteatosis by enhancing mitochondrial oxidative metabolism via heme oxygenase- 1 . Nutr Metab 2015;12:33. https://doi.org/10.1186/s12986-015-0030-5

44.Zhou Y, Mao S, Zhou M. Effect of the flavonoid baicalein as a feed additive on the growth performance, immunity, and antioxidant capacity of broiler chickens. Poult Sci 2019;98: 2790-9. https://doi.org/10.3382/ps/pez071

45.Liu X, Yoon SB, Kim IH. Growth performance, nutrient digestibility, blood profiles, excreta microbial counts, meat quality and organ weight on broilers fed with de-oiled lecithin emulsifier. Animals 2020;10:478. https://doi.org/10.3390/ ani10030478

46. Yugarani T, Tan BKH, Teh M, Das NP. Effects of polyphenolic natural products on the lipid profiles of rats fed high fat diets. Lipids 1992;27:181-6. https://doi.org/10.1007/BF02536175

47.Egert S, Boesch-Saadatmandi C, Wolffram S, Rimbach G, Müller MJ. Serum lipid and blood pressure responses to quercetin vary in overweight patients by apolipoprotein $\mathrm{E}$ genotype. J Nutr 2010;140:278-84. https://doi.org/10.3945/ jn.109.117655

48. Simitzis P, Spanou D, Glastra N, Goliomytis M. Impact of dietary quercetin on laying hen performance, egg quality and yolk oxidative stability. Anim Feed Sci Technol 2018;239: 27-32. https://doi.org/10.1016/j.anifeedsci.2018.03.004

49.Jung CH, Cho I, Ahn J, Jeon TI, Ha TY. Quercetin reduces high-fat diet-induced fat accumulation in the liver by regulating lipid metabolism genes. Phytother Res 2013;27:139-43. https://doi.org/10.1002/ptr.4687

50. Santoso U, Kususiyan K, Suharyanto S. The effect of Sauropus androgynus leaves extract plus turmeric powder on fat deposition, carcass quality and blood profile in broilers fed low protein diets. J Indones Trop Anim Agric 2015;40:121-30. https://doi.org/10.14710/jitaa.40.2.121-130

51.Payne RL, Bidner TD, Southern LL, McMillin KW. Dietary effects of soy isoflavones on growth and carcass traits of commercial broilers. Poult Sci 2001;80:1201-7. https://doi. org $/ 10.1093 / \mathrm{ps} / 80.8 .1201$

52. Chan ST, Chuang CH, Lin YC, Liao JW, Lii CK, Yeh SL. Quercetin enhances the antitumor effect of trichostatin A and suppresses muscle wasting in tumor-bearing mice. Food Funct 2018;9:871-9. https://doi.org/10.1039/C7FO01444A 
53. Kamboh AA, Zhu WY. Effect of increasing levels of bioflavonoids in broiler feed on plasma anti-oxidative potential, lipid metabolites, and fatty acid composition of meat. Poult Sci 2013;92:454-61. https://doi.org/10.3382/ps.2012-02584

54.Liu Y, Li Y, Liu HN, et al. Effect of quercetin on performance and egg quality during the late laying period of hens. Br Poult Sci 2013;54:510-4. https://doi.org/10.1080/00071668.2013. 799758

55.Svihus B. The gizzard: function, influence of diet structure and effects on nutrient availability. World's Poult Sci J 2011; 67:207-24. https://doi.org/10.1017/S0043933911000249

56.Iftikhar H, Mahmood MS, Arshad MI, Akhtar M, Mahmood F, Rafique A. Immune system dysfunction in broiler chickens experimentally inoculated with fowl adenovirus serotype- 4 associated with inclusion body hepatitis hydropericardium syndrome. Turk J Vet Anim Sci 2012;36:223-30. https://doi. org/10.3906/vet-0807-21

57. Chouliara E, Karatapanis A, Savvaidis IN, Kontominas MG. Combined effect of oregano essential oil and modified atmosphere packaging on shelf-life extension of fresh chicken breast meat, stored at $4^{\circ} \mathrm{C}$. Food Microbiol 2007;24:607-17. https://doi.org/10.1016/j.fm.2006.12.005

58. Nissen PM, Young JF. Creatine monohydrate and glucose supplementation to slow- and fast-growing chickens changes the postmortem $\mathrm{pH}$ in pectoralis major. Poult Sci 2006;85: 1038-44. https://doi.org/10.1093/ps/85.6.1038

59. Otto G, Roehe R, Looft H, et al. Drip loss of case-ready meat and of premium cuts and their associations with earlier measured sample drip loss, meat quality and carcass traits in pigs. Meat Sci 2006;72:680-7. https://doi.org/10.1016/j. meatsci.2005.10.001

60.Luciano G, Monahan FJ, Vasta V, Pennisi P, Bella M, Priolo A. Lipid and colour stability of meat from lambs fed fresh herbage or concentrate. Meat Sci 2009;82:193-9. https://doi.org/ 10.1016/j.meatsci.2009.01.010

61.Li Y, Yu C, Li J, Zhang L, Gao F, Zhou G. Effects of dietary energy sources on early postmortem muscle metabolism of finishing pigs. Asia-Australas J Anim Sci 2017;30:1764-72. https://doi.org/10.5713/ajas.17.0090

62. Jiang ZY, Jiang SQ, Lin YC, Xi PB, Yu DQ, Wu TX. Effects of soybean isoflavone on growth performance, meat quality, and antioxidation in male broilers. Poult Sci 2007;86:135662. https://doi.org/10.1093/ps/86.7.1356

63. Chang Q, Zuo Z, Chow MSS, Ho WKK. Difference in absorption of the two structurally similar flavonoid glycosides, hyperoside and isoquercitrin, in rats. Eur J Pharm Biopharm 2005;59:549-55. https://doi.org/10.1016/j.ejpb.2004.10.004

64. Kumar D, Tanwar VK. Utilization of clove powder as phytopreservative for chicken nuggets preparation. J Stored Prod Postharvest Res 2011;2:11-4.

65.Dang DX, Kim IH. Effects of dietary supplementation of Quillaja saponin on growth performance, nutrient digestibility, fecal gas emissions, and meat quality in finishing pigs. J Appl Anim Res 2020;48:397-401. https://doi.org/10.1080/097121 19.2020.1813739

66. Ngapo TM, Martin JF, Dransfield E. International preferences for pork appearance: I. Consumer choices. Food Qual Prefer 2007;18:26-36. https://doi.org/10.1016/j.foodqual.2005.07. 001 